\title{
VALERA ESCRIBE UN SONETO DE ZORILLA: SOBRE LA HERMANDAD LÍRICA DE LOS ROMÁNTICOS
}

Leonardo ROMERO TOBAR Universidad de Zaragoza

No se puede decir que Valera fuese un «romántico» a pesar de su encuentro infantil con Espronceda y de sus intervenciones en las fiestas de sociedad romántica en Granada, en Madrid y en el Nápoles de los años cuarenta. Su posición crítica respecto al romanticismo español quedó establecida en su trabajo de 1854 «Del Romanticismo en España y de Espronceda» y en muchas otras páginas posteriores, de las que no resultan las menos significativas las que escribió para su continuación de la Historia de España de Modesto Lafuente, textos de los que me he ocupado en otros lugares (Romero Tobar 2002; 2004, págs. LXIVLXVI).

La idea de la poesía que mantuvo Valera respondía a una amplia concepción de la lírica moderna -desde Goethe y los románticos alemanes hasta Leopardi-y se situaba, por supuesto, en los antípodas del exceso verbal de la escrita en España por los poetas del círculo esproncediano y los que vinieron después. Pero entre los poetas románticos españoles, Zorrilla era una presencia imprescindible y a él le dedicó Valera bastantes páginas de crítica y comentario. Una lectura apresurada de estas páginas puede establecer la diferenciación convencional entre un Valera escasamente sincero en las páginas publicadas y el Valera exigente y agudo de las cartas privadas. Pero tal impresión ni es exacta ni responde a una inmóvil actitud mantenida durante toda su trayectoria de escritos. 
Desde luego que si buscamos entre las cartas más antiguas del andaluz, pronto encontramos referencias y alusiones al autor del Tenorio'; unas veces, meramente descriptivas («con la edición de autores que Baudry publica en París, se han popularizado un poco en este reino [Portugal] Zorrilla y Espronceda» escribe a Estébanez en 24-I-1851) y otras, de tono indudablemente despectivo ( $C$ Celebro infinito que los poetas coman turrón a dos carillos, y desearía que también se le diesen a Zorrilla, para que no nos aturdiese y angustiase el alma con aquel maremágnum palabrero de su Granada» en comunicación al mismo corresponsal en 10-XI-1853). En las páginas de los periódicos no fue Valera menos insincero a la hora de valorar la obra poética del castellano. Escribía, por ejemplo, en el famoso artículo de 1854:

Zorrilla es otro de los corifeos del romanticismo, y el más fecundo de todos. Poeta de más imaginación que sentimiento y gusto, es incorrecto y descuidado a veces, y a veces elegante, como por instinto. Florido, pomposo, arrebatado, sublime, vulgar, enérgico y conciso, desleido y verboso, todo lo es sucesivamente, según la cuerda que toca, pero siempre simpático y nuevo, siempre popular y leído con placer y aplaudido y querido con frenesí de los españoles (Valera 1949, pág. 13).

Cierto que hay cartas en las que el juicio no puede ser más negativo, como en este fragmento de una dirigida a Gumersindo Laverde: «Yo no estimaba mucho a Zorrilla, pero le prestaba más mérito del que hoy le doy. Su lectura casi me es insufrible. ¡Qué falta de ideas! ¡Cuánta puerilidad! ¡Cuánto desatino! Y, sobre todo, iqué abundancia de palabras y qué pobreza de sentido! (carta de 26-IV1866). Aunque el regreso del poeta en julio de 1866, después de su experiencia americana, debió de poner en relación a ambos escritores, que iniciaron una amistad profesional de mutua estima, singularmente delicada por parte de Valera. Así los vemos coincidir en reuniones de escritores: «Mucho sentí que no te quedases aquí para asistir a mi escrúpulo de tertulia literaria, donde Zorrilla nos leyó trozos de su Leyenda del Cid. Aunque le sobra de pane lucrando, tiene algo bueno, y además no se pasó mal el rato con la conversación» escribe a Sofía Valera el 23II-1871. «Ahora vienen los viernes a mi casa unos cuantos poetas y se leen versos. Anoche duró la fiesta hasta las $21 / 2$ de la madrugada. Estuvo Zorrilla, y de los jóvenes el más brillante es Pepe Alcalá Galiano, nieto de don Antonio» reitera a su hermana en carta de $10-$ II- $1877^{2}$.

El ingreso del poeta en la Academia sorprendió en Lisboa al diplomático, desde donde escribe a otros compañeros de la Casa comentando la elección. «Veo

' Las referencias a las cartas de Juan Valera se hacen sobre la edición de la Correspondencia que estoy publicando (hasta ahora, cuatro volumenes editados).

2Véanse también cartas a Sofia (18-III-1877 y 4-V-1878); a Latino Coelho (31-III-1877). 
que han elegido Vds. académico a Zorrilla. Espero que esta vez escribirá y leerá el discurso y entrará) comenta a Manuel Cañete (carta de 4-XI-1882). Comentario que extiende en su comunicación a Tamayo y Baus: «Mucho celebro que sea Zorrilla académico. Nada más justo y conveniente. Hallo, no obstante, una extravagancia esa de leer una leyenda en vez de un discurso, y preferiré que Zorrilla escriba y lea un discurso en prosa, sea bueno o malo»(carta de 13-XI-1882). Por estas fechas, precisamente, aparecía la continuación de la Historia de Modesto Lafuente en la que Valera dedicaba páginas muy comprensivas a la obra del poeta castellano y se detenía en señalar sus valores indiscutibles:

Muy fácil scría marcar los defectos de que las obras de Zorrilla adolecen. Tal vez en ocasiones es incomprensible por lo vago; tal vez prolijo, tal vez, falso y vulgar; pero en las mismas composiciones en que la inspiración desfallece y en que más se muestran tan graves defectos, hay tal encanto de armonía y de gracia para los oídos españoles, que nos complacemos en oírlas, las guardamos en la memoria y las repetimos embelesados. Estos defectos, además, se nos aparecen como inevitables. Apenas concebimos sin ellos la espontaneidad sobrehumana del poeta, que canta por instinto, como cantan las aves, y en quien parece cierto, y no vaga imagen de la poesía, aquello que él mismo declara de que hay un ser misterioso, un demonio o espíritu, que le posee y que le dicta lo que escribe. (Valera 2004, pág. 93)

Y, aunque en ocasiones Valera había sugerido la situación de forzado de la pluma en que vivía Zorrilla, los años «de senectute» atenúan las reservas del crítico e incrementan la atención del amigo al colega necesitado: "Y no se diga que en esto de rebajar somos crueles, más cruel es el público pasando de un extremo a otro. Por ello no aguarda a veces a que el autor muera; testigo, Zorrilla, con quien es el público más que severo, injusto e ingrato, aunque le dé pensiones» escribe a Menéndez Pelayo en carta de 19-VI-1883. Esta simpatía piadosa es paralela a la dulcificación de las estimaciones críticas que le merecen las obras poéticas del vallisoletano: «Zorrilla, a pesar de su palabrería, es admirable» confiesa a su íntimo el barón de Greindl (carta de 12-IX-1887) adelantando las valoraciones que formulará en la serie titulada "La poesía lírica y épica en la España del siglo XIX») de La Ilustración Española y Americana (1901-1902) y en el Florilegio de $1902^{3}$.

En la confianza que mantenía con el diplomático belga Greindl le expone en muchas ocasiones anécdotas y estimaciones sobre los escritores españoles contemporáneos; en carta de 6-XI-1890, por ejemplo, le da cuenta del error económico de Zorrilla al haber vendido sus derechos de autor sobre las representaciones teatrales del Tenorio: "Como esto produce, cada año, unos cuantos miles de duros al propietario de la obra, y Zorrilla la vendió por 3.000 reales de vellón, es de ver

Los textos pueden leerse en Valera 1949, 1223- 1229 y 1338-1342. 
y de oír el furor de Zorrilla y su deseo de desacreditar, sin conseguirlo, su obra tan popular y tan acreditada» (carta de 6-XI-1890). Y en la noticia biográfica que le dedica en el Florilegio de poesias castellanas del siglo XIX (1902-1903) es más explícito aún en lo que a noticias económicas se refiere; recuerda que, a su regreso de Méjico, Zorrilla volvió «tan falto de recursos como de costumbre» y que el ministro de Fomento Ruiz Zorrilla le encargó a él mismo, a la sazón Director General del ministerio, una fórmula administrativa que permitiese conceder una pensión oficial al poeta. «La fundación piadosa de Montserrat, que tenemos en Roma y que el ministro de Estado administra, produce una renta de unos cuantos miles de duros. De ellos propuse a don Cristino que diera a Zorrilla tres mil anuales; pero a don Cristino le pareció poco y concedió cuatro mil» (Valera 1949, 1342 a). Otro ministro eliminó la ayuda.

Esta «sindineritis» del poeta -enfermedad bien conocida por el propio Valera- tuvo malos remedios durante los últimos años de su vida hasta el punto que, a su muerte, iniciativas de instituciones públicas -como el Ayuntamiento de Valladolid y la Real Academia Española-idearon procedimientos para conseguir recursos dinerarios que valieran a la viuda del poeta.

Entre estas iniciativas de atención económica debe inscribirse el premio de mil pesetas que la Española concedió a un soneto firmado por Zorrilla y que había concurrido a un concurso de la institución. Su enfermedad y su muerte, acaecida en la noche del 22 al 23 de enero de 1893, fueron ampliamente seguidas por los periódicos así como las exequias fúnebres que tuvieron el aura oficial de que se lucraban los escritores famosos de estos años (Alonso Cortés 1943b, págs. 936-975). Valera daba a Greindl un breve apunte sobre el acontecimiento: «Nuestro famoso poeta Zorrilla murió, tres o cuatro días ha. Nadie, en vida, hacía caso de él, y él vivía miserablemente, oscurecido, olvidado, en un $5^{\circ}$ piso, casi ya en el cielo. Ahora, con su muerte, todos a porfía le ensalzan y procuran hacer su apoteosis, moviéndonos a recordar, aunque sea irreverente y absurdo en esta ocasión, el proverbio que dice: al asno muerto, la cebada al rabo. El entierro del glorioso trovador fue pomposísimo. Le costeó la Real Academia Española. Yo tuve la honra de llevar una de las cintas del féretro en nombre de dicha Academia. En el Ateneo habrá velada literaria, donde se leerán poesías de Zorrilla, y Moret hará su panegírico. El Gobierno celebrará magníficas exequias en San Francisco el Grande, templo restaurado donde han echado el resto nuestros más hábiles pintores, escultores en bronce, piedra y madera. San Francisco el Grande es, a la verdad, en el día, un espléndido monumento. Se trata también de erigir a Zorrilla una buena estatua» (carta de 28-I-1893).

El soneto premiado se titula «A Isabel la Católica. Por el Descubrimiento de América», apareció en varios periódicos madrileños (La Época y El Imparcial del 27-II-1893) y de él anota su moderno recopilador en las Obras Completas de 
Zorrilla: «Presentó Zorrilla, poco antes de morir, en un concurso destinado a premiar con 1000 pesetas, donativo de don Waldo Vizoso, el mejor soneto dedicado a Isabel la Católica por el descubrimiento de América. El jurado compuesto por la Sra. Pardo Bazán y los Sres. Valera y Castelar concedió el premio a este soneto de Zorrilla, cuando el poeta había ya fallecido» (Alonso Cortés 1943a, pág. 2206).

No se tenían más noticias ni sobre el concurso - a la zaga de los fastos de 1892 en que Valera representó un notable papel- ni sobre el soneto hasta que llegó a mi conocimiento un estudio sobre Juan Valera, texto mecanografiado inédito, que se conserva en la Casa-Museo de José María de Cossío de Tudanca (Cantabria) que se titula El incomparable don Juan Valera y cuyo autor es el polifacético Estanislao Quiroga y de Abarca que debió de redactar este texto en la década de los cuarenta, ya que se lo envió a Cossío con carta fechada el 3-VII$1952^{4}$.

Este trabajo, hecho con la ayuda de la hija de Valera, responde a la línea de admiración sin fisuras que la persona y la obra del egabrense ha suscitado en un tipo determinado de lectores españoles del primer tercio del siglo XX, y contiene noticias y datos que pueden ser útiles para la biografía de Valera, una vez sometidos a la debida criba. Una de esas noticias señala escuetamente que el soneto de Zorrilla premiado por la comisión académica de la que formaba parte don Juan había sido «hecho por Valera para favorecer económicamente a la viuda de Zorrilla y presentado con tal fin a un concurso convocado por la Real Academia Española cuando se iba a declarar desierto» y en nota a pie de página señala el lema que identificaba al soneto: «Alter erit tum Tiphys, et altera quae vehat Argo delectos heroas» («Otro Tifis habrá y otro Argos que conduzca a los héroes escogidos..»).

La noticia no sería relevante si no contase, además de con las habilidades sociales de don Juan para esta clase de artificios benefactores tan diversos del actual «spoil system» que caracteriza el mecenazgo literario, con un componente estrictamente literario como es el escaso empleo del soneto que hizo Zorrilla frente a su correcto cultivo por parte del cordobés $y$, singularmente, que la cita latina que sirve de lema al soneto (versos 34-35 de la Égloga IV de Virgilio) era un texto singularmente familiar para Valera que lo estimaba capital en la serie que construye el tópico de la «Edad de Oro» y que él mismo empleó como referencia explícita a las proezas de portugueses y castellanos en los confines orientales y occidentales del globo. Estos versos latinos, junto con otra cita de Os Lusiadas, preceden, en cita liminar, a las páginas narrativas de Morsamor.

${ }^{4}$ Casona de Tudanca, Ms. 122. 


\section{A ISABEL LA CATÓLICA \\ POR EL DESCUBRIMIENTO DE AMÉRICA}

Vencedora en Granada, hallas mezquino

el mundo antiguo, en la sublime idea

que de tu pueblo tienes, y desea

abrir tu alma a su expansión caminos.

Proteges a Colón, y el peregrino

plan se logra por ti, que la europea

ciencia extendiendo, en cuanto el mar rodea

planta la Cruz del Redentor divino.

Así tu gloria América proclama, y a las naves de Hirán causa desdoro

y al bienhechor ejército de Osiris.

Sorata te alza al éter; Tequendama le hunde en tu aplauso; Niágara sonoro como limbo de luz te ciñe el iris. 


\section{BIBLIOGRAFÍA}

AlONSO CORTÉS, Narciso 1943 b. Zorrilla. Su vida y sus obras, Valladolid, librería Santarén.

ROMERO TOBAR, Leonardo, 1993-1994. «Zorrilla y las fiestas del imperio mejicano», Explicación de textos literarios, (Sacramento), XXII-2, págs. 43-57.

- 2002. «1854, el Romanticismo reexaminado», AA. VV., Romanticismo, 8. Los románticos teorizan sobre sí mismos, Bologna, Il Capitello del Sole, págs. 193-207.

VALERA, Juan, 1949. Obras Completas, Madrid, Aguilar, vol. I.

- (1847-1905), 2002-pendiente de conclusión, Correspondencia, ed. de Leonardo Romero Tobar (dir.), Ángeles Ezama y Enrique Serrano, Madrid, Castalia, publicados vols. I-IV.

- (1882), 2004. Obra histórica, Leonardo Romero Tobar (ed.), Pamplona, Urgoiti editores.

Zorrilla, José 1943 a. Obras Completas, Narciso AlOnso CORTÉs (ed.), Valladolid, Librería Santarén, vol. II. 